(C) Österreichische Apotheker-Verlagsgesellschaft m. b. H, Wien, Printed in Austria

\title{
Colorimetric and Titrimetric Methods for Determination of Some Cephalosporins in their Pure and Dosage Forms.
}

\author{
Hisham E. Abdellatef, Abdalla A. Shalaby, \\ Heba M. Elsaid and Magda M. Ayad \\ Analytical Chemistry Department, Faculty of Pharmacy, \\ Zagazig University, Zagazig, Egypt
}

\begin{abstract}
Two colorimetric and titrimetric procedures are developed for determination of some cephalosporins, namely, cefotaxime sodium (CFT), cefuroxime sodium (CFU) and ceftazidime pentahydrate (CFZ). The first method, a colorimetric method, was based on the reaction of these cited drugs with 4-chloro-7nitrobenzofurazan (NBD-Cl), in the presence of $5 \times 10^{-3} \mathrm{M}$ borax, with the formation of stable colored chromogens with maximum absorbance in the range of $409-414$ $\mathrm{nm}$. All variables affecting the development of the colour have been investigated and the conditions were optimized. The method obeys Beer's law over concentration ranges of $19.09-95.49,17.85-124.98$ and $63.66-254.66 \mu \mathrm{g} \mathrm{ml}^{-1}$ of CFT, CFU and CFZ, respectively. Obedience to Beer's law permitted the successful application of the proposed method for the assay of cefuran, cefumax and fortum vials. The results obtained reveal good percentage recoveries, which are in good agreement with those obtained by the official methods. In the second method, the titrimetric method, the conditions for the oxidimetric titration of cephalosporins have been studied. The titration takes place because of catalytic quantities of $\mathrm{KBr}$, which give rise to an intermediate that can be hydrolyzed to the sulfoxide. The operating conditions are described and a hypothesis is put forward concerning the mechanism of the reaction.
\end{abstract}

\section{Introduction:}

Cephalosporins are penicillinase-resistant antibiotics with significant activity against both gram-negative and gram-positive bacteria. Several procedures have been reported in the literature for the analysis of cephalosporins. These methods are spectrophotometry (1-5), high performance liquid chromatography $(6,7)$, capillary electrophoresis (8), fluorimetry (9), polarography (10) and voltammetry (11). The USP XXIII (12) specify high performance liquid chromatography for the 
determination of cefuroxime sodium (CFU), cefotaxime sodium (CFT) and ceftazidime pentahydrate (CFZ).

NBD-Cl has been reported as fluoregenic reagent for the determination of amines (13). Thiocompounds have been reported to form intensely coloured products in an alkaline medium with NBD-Cl which could be used for their colorimetric determination (14). Therefore, it was decided, on the basis of these facts, to develop a quantitative method for determination of the previous mentioned cephalosporins with $\mathrm{NBD}-\mathrm{Cl}$, which may be used for their analysis either in pure form or in pharmaceutical formulations.

On the other hand, with the aim of investigating the nucleophilic character of thioethers of pharmaceutical interest, and in order to develop rapid and precise methods for the analysis of products and intermediates containing the R-S- $R_{1}$ group, we study the possibility of titrating cephalosporins by potentiometric techniques. The ability of thioethers to take part in addition reactions with halogens, forming derivatives of the type:

$$
\underset{\mathrm{R}_{1}^{\prime}}{\mathrm{R}} \mathrm{S} \cdot \mathrm{X}_{2} \leftrightarrow\left[\begin{array}{l}
\mathrm{R}^{\prime} \mathrm{S}^{+}-\mathrm{X} \\
\mathrm{R}_{1}^{\prime}
\end{array}\right] \mathrm{X}^{-}
$$

is well known. In an aqueous acidic environment these derivatives give rise to the corresponding sulfoxides. Bromine (or NBS) readily forms compounds of the type indicated above (better than the other halogens) under ordinary reaction conditions. If the hypothesis concerning the possible formation of dihalogen derivatives were valid for all sulfides, then even the most unreactive thioethers should be readily oxidized to sulfoxides with an oxidizing agent of appropriate strength, such as a salt of tetravalent lead for example, provided that traces of bromine were present (15). Rather than using bromine itself, we should also obtain the same results with $\mathrm{KBr}$, which give rise to bromine in an oxidizing medium.

The propose of the present work is to describe the development of two simple and accurate colorimetric and titrimetric methods for the analysis of three cephalosporin derivatives.

\section{EXPERIMENTAL}

\section{I-Apparatus}

A- Shimadzu 260 UV recording spectrophotometer 
B- Jenway $3010 \mathrm{pH}$ meter

C- Double junction platinum electrode

\section{II- Materials and reagents}

All the reagents were of analytical grade. Double distilled water was used

1. Cefotaxime sodium, Hoechst orient Egypt, Cairo, under the licence from Hoechst AG Frankfurt (Main) Germany.

2. Cefuroxime sodium, Glaxo Egypt, SAE Cairo, under the licence from Glaxo Group, England.

3. Ceftazidime pentahydrate, Glaxo Egypt, SAE Cairo, under the licence from Glaxo Group, England.

4. 4- Chloro-7-nitrobenzo-furazan (Aldrich), was prepared as $2 \times 10^{-2} \mathrm{M}$ solution in acetone, a fresh solution is prepared daily.

5. Borax (EL-Nasr Chemical Co., Egypt) was prepared as $5 \times 10^{-3} \mathrm{M}$ in distilled water.

6. 0.1 N Sodium hydroxide

7. $0.1 \mathrm{~N}$ Hydrochloric acid.

8. $0.1 \mathrm{~N}$ Lead tetraacetate.

9. $2.5 \times 10^{-4} \mathrm{M}$ of $\mathrm{KBr}$.

\section{III-Standard solutions:}

\section{Solutions for colorimetric determination:}

$2 \times 10^{-3} \mathrm{M}$ solution of CFT, CFU and CFZ was prepared by dissolving $95.49,89.27$ and $127.33 \mathrm{mg}$, respectively in $10 \mathrm{ml}$ bidistilled water, mixing with $10 \mathrm{ml} 0.1 \mathrm{~N}$ $\mathrm{NaOH}$ and placing in water bath at $95{ }^{\circ} \mathrm{C}$ for $25 \mathrm{~min}$. After hydrolysis, the mixture is cooled, neutralized to $\mathrm{pH} 7$ with $0.1 \mathrm{~N} \mathrm{HCl}$ and diluted to $100 \mathrm{ml}$ with bidistilled water.

\section{Solutions for titrimetric determination:}

$1.75 \times 10^{-2} \mathrm{M}$ solution of CFT, CFU and CFZ was prepared by dissolving 83.55, 78.81 and $111.40 \mathrm{mg}$, respectively in $10 \mathrm{ml}$ bidistilled water.

\section{IV- Formulations:}

The following commercial formulations were subjected to the analytical procedures: 
1.Cefuran vials (Pharco Pharmaceuticals, Egypt) containing $524 \mathrm{mg}$ cefotaxime sodium equivalent to $500 \mathrm{mg}$ cefotaxime.

2.Cefumax vials (Pharco Pharmaceuticals, Egypt) containing cefuroxime sodium equivalent to $250 \mathrm{mg}$ cefuroxime.

3.Fortum vials (Glaxo S.A.E. Egypt) containing $250 \mathrm{mg}$ ceftazidime as sodium salt.

\section{PROCEDURES}

\section{A-Colorimetric procedure:}

Different aliquots of the standard drug solution in the concentration range stated in table 1 , were placed in 10-ml volumetric flasks, followed by $2 \mathrm{ml}$ of $5 \times 10^{-3} \mathrm{M}$ borax and $0.1 \mathrm{ml}$ of $2 \times 10^{-2} \mathrm{M}$ of NBD-Cl, mixed well and allowed to stand for $30 \mathrm{~min}$. at room temperature. $1 \mathrm{ml} 0.1 \mathrm{~N} \mathrm{HCl}$ was added and the volume was completed with methanol. The absorbance was measured at $409-414 \mathrm{~nm}$ against blank in which the drug was omitted.

Table (1): Parameters for the spectrophotometric determination of cefotaxime sodium, cefuroxime sodium and ceftazidime pentahydrate using NBD-Cl

\begin{tabular}{|c|c|c|c|}
\hline \begin{tabular}{|l|} 
Parameters \\
\end{tabular} & Cefotaxime & Cefuroxime & Ceftazidime \\
\hline Beer's law limits $\left(\mu \mathrm{gml}^{-1}\right)$ & $19.09-95.49$ & $17.85-124.98$ & $63.66-254.66$ \\
\hline Molar absorptivity $\left(\mathrm{mol}^{-1} \mathrm{~cm}^{-1}\right)$ & $4.83 \times 10^{3}$ & $3.45 \times 10^{3}$ & $2.11 \times 10^{3}$ \\
\hline Regression equation: & & & \\
\hline Slope (b) & 0.0100 & 0.0076 & 0.0032 \\
\hline Intercept (a) & 0.0046 & 0.0034 & 0.0107 \\
\hline Correlation coefficient ( $r$ ) & 0.9996 & 0.9996 & 0.9992 \\
\hline Relative standard deviation (\%) & 0.7364 & 1.2466 & 1.0194 \\
\hline
\end{tabular}

\section{B-Titrimetric procedure:}

$1 \mathrm{ml}$ of standard solution for titrimetric procedure was dissolved in $70 \mathrm{ml}$ of a $70 \%$ solution of acetic acid water. $2.5 \times 10^{-4} \mathrm{M}$ of $\mathrm{KBr}$ was added and the solution was titrated with $0.1 \mathrm{~N}$ lead tetraacetate solution. The titrant was added at a rate of $1 \mathrm{ml} /$ 
min and the end point was detected potentiometrically. The reaction rate was comparable to that of the usual neutralization reactions

\section{Procedure for pharmaceutical formulations}

For colorimetric method, the procedure described in the above section (A). was followed using solution of Cefuran vial $\left(0.95 \mathrm{mgml}^{-1}\right.$ cefotaxime sodium), Cefumax vial $\left(0.89 \mathrm{mgml}^{-1}\right.$ cefuroxime sodium) or Fortum vial $\left(1.27 \mathrm{mgml}^{-1}\right.$ ceftazidime pentahydrate) in distilled water. For titrimetric method, the procedure given in the above section (B) was adopted using solution of Cefuran vial $\left(8.35 \mathrm{mgml}^{-1}\right.$ cefotaxime sodium), Cefumax vial $\left(7.88 \mathrm{mgml}^{-1}\right.$ cefuroxime sodium) or Fortum vial (11.14 $\mathrm{mgml}^{-1}$ ceftazidime pentahydrate) in distilled water.

\section{RESULTS AND DISCUSSION}

\section{$\underline{\text { A-Colorimetric method }}$}

In this work, the reaction of the hydrolysis product of the three cephalosporins, which have free -SH group (Scheme 1), with NBD-Cl reagent was studied.

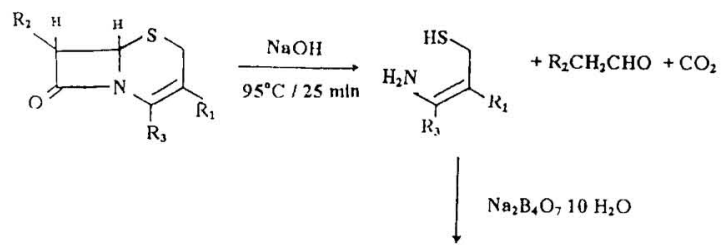

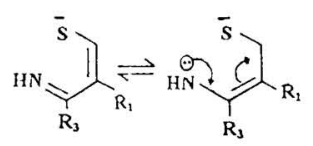<smiles>O=[N+]([O-])c1ccc(Cl)c2nonc12</smiles>

\section{Scheme 1}

The reaction of cephalosporins with NBD-CI.<smiles>[R3]C(=N)/C=C\Sc1ccc([N+](=O)[O-])c2nonc12</smiles> 
The method is based on the high nucleophilicity of thiol group and the ability of $\mathrm{NBD}-\mathrm{Cl}$ to couple with it through $\mathrm{SN}_{2}$ reaction giving yellow colour with $\lambda_{\max }$ at 414 nm (Figure 1).



Figure (1)

Absorption spectra of $53.56 \mu \mathrm{gml}^{-1}$ cefuroxime sodium $(\ldots \ldots \ldots), 0.1 \mathrm{ml}$ of $0.02 \mathrm{M}$ $\mathrm{NBD}-\mathrm{Cl}\left({ }^{-} ._{-}\right)$and their reaction product in methanol

All conditions studied were optimized at room temperature $\left(25 \pm 5^{\circ} \mathrm{C}\right)$. A volume of $0.04,0.04$ or $0.1 \mathrm{ml}$ of $\mathrm{NBD}-\mathrm{Cl}$ solution $\left(2 \times 10^{-2} \mathrm{M}\right)$ in acetone was found to be satisfactory for CFT, CFZ and CFU, respectively. Large excess of reagent was followed by disappearance of the peak at the specific $\lambda_{\max }$ and the appearance of another peak at $378 \mathrm{~nm}$. Owing to the presence of labile chloride, a daily fresh solution is prepared. To generate nucleophile(s) from the studied drugs, $2 \mathrm{ml}$ of $5 \times 10^{-3} \mathrm{M}$ of borax was used. The time required for the reaction to be completed was found to be $30 \mathrm{~min}$., and the colour was stable for $24 \mathrm{~h}$. Addition of $1 \mathrm{ml}$ of $0.1 \mathrm{~N}$ $\mathrm{HCl}$ was essential to stabilize the chromogen formed and neutralize the excess borax. Different dilution solvents have been tried (Table 2), methanol, isopropanol and 
acetonitrile gave best results. Concerning the stoichiometric relationships, the molar ratio method indicated a molar ratio $2: 1$ cephalosporins (thiol) to NBD-Cl.

Table (2) - Effect of solvent on the absorption intensity of reaction product of cefuroxime sodium $\left(47.74 \mu \mathrm{gml}^{-1}\right)$ with NBD-Cl

\begin{tabular}{|l|l|l|}
\hline Solvent & $\lambda_{\max }$ & Absorbance \\
\hline Water & 419.2 & 0.522 \\
Ethanol & 412.4 & 0.515 \\
Methanol & 412.6 & 0.555 \\
Isopropanol & 411.8 & 0.545 \\
Acetone & 411.2 & 0.494 \\
Dioxan & 412.4 & 0.531 \\
Acetonitrile & 409.9 & 0.550 \\
\hline
\end{tabular}

\section{B- Titrimetric method}

The method described above was applied to the cyclic thioether contained in the cephalosporins. Figure 2 show the potentiometric titration curve of cefuroxime sodium with $0.1 \mathrm{~N} \mathrm{~Pb}\left(\mathrm{CH}_{3} \mathrm{COO}\right)_{4}$ in $70 \%$ acetic acid in absence and presence of $\mathrm{KBr}$ (mole ratio of $\mathrm{KBr}$ to cephalosporins of 1:1, 1:25, 1:50 and 1:100). As to the titration, the same results is obtained with bromine water, NBS, or potassium bromide. For practical reasons we used potassium bromide. For a good titration the minimum quantity of the catalyst can be used is $1 \mathrm{~mol}$ of potassium bromide to $1 \mathrm{~mol}$ of cephalosporins. The explanation for this reaction may be as follows:

$2 \mathrm{Br}^{-} \stackrel{\text { Oxidation }}{\longrightarrow} \mathrm{Br}_{2}$

Immediately the following series of reactions is preferred

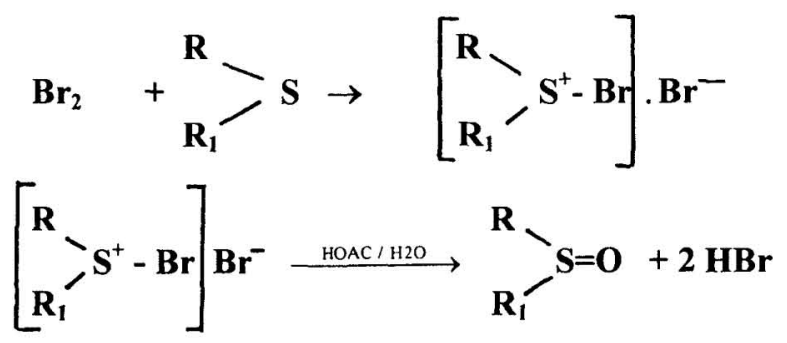


The hydrobromic acid liberated is continuously oxidized by the oxidizing agent added during the titration and is immediately used again. Because of the titration curve does not permit a clear differentiation between the potential jump associated with oxidation of cephalosporins and that associated with oxidation of the bromide, it is acceptable, for analytical purposes, to carry out a blank titration with the solvent containing the appropriate amount of catalyst and to subtract the corresponding volume of titrant from the subsequent titration.

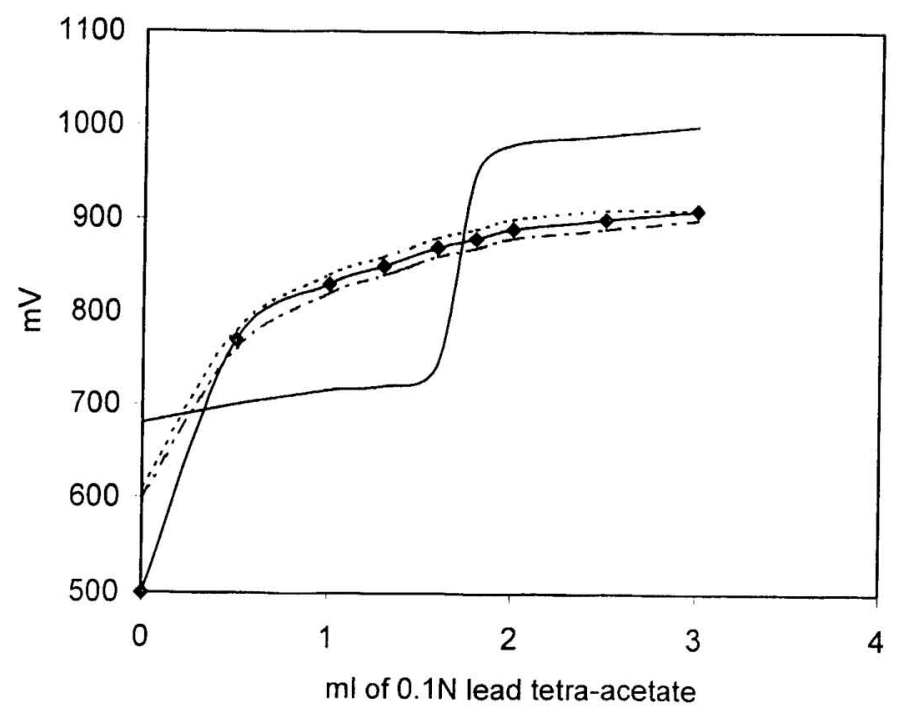

Figur (2)

Titration of cefuroxime sodium with $0.1 \mathrm{~N} \mathrm{~Pb}\left(\mathrm{CH}_{3} \mathrm{COO}\right)_{4}$ in $70 \%$ acetic acid in absence (---) and presence of $\mathrm{KBr}$ [mole ratio of $\mathrm{KBr}$ to cefuroxime of $1: 1$

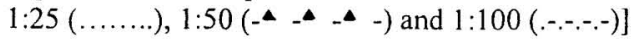

\section{Ouantification, accuracy and precision:}

For the colorimetric method a linear correlation was found between absorbance and concentration in the ranges given in table 1. The correlation coefficients, intercepts and slopes for the calibration data for the three cited drugs are calculated using the least-squares method.

The precision and accuracy of the two methods were tested by estimating five replicates of the three cephalosporins. The percentage standard deviation and the standard analytical error, can be considered to be very satisfactory (Table $3 \& 4$ ). 
The utility of each method was verified by means of replicate measurements of the pharmaceutical formulations and recovery experiments. Recoveries were determined by adding standard drug to the pre-analyzed mixture of pharmaceutical preparations. The results of recovery experiments by the proposed methods are listed in Table 4.

Table (3): Evalution of the accuracy and precision of the titrimetric procedure

\begin{tabular}{|c|c|c|c|c|}
\hline Compound & Added mg & Found $\pm \mathrm{SD}^{*}$ & RSD\% & $\overline{\text { SAE }}$ \\
\hline Cefotaxime & $\begin{array}{l}8.355 \\
16.711 \\
25.067\end{array}$ & $\begin{array}{r}8.41 \pm 0.16 \\
16.83 \pm 0.37 \\
25.44 \pm 0.53\end{array}$ & $\begin{array}{l}1.90 \\
2.20 \\
2.08 \\
2.06\end{array}$ & $\begin{array}{l}0.072 \\
0.165 \\
0.237 \\
0.158\end{array}$ \\
\hline Cefuroxime & $\begin{array}{l}7.812 \\
15.623 \\
23.424\end{array}$ & $\begin{array}{c}7.73 \pm 0.13 \\
14.99 \pm 0.19 \\
23.00 \pm 0.26\end{array}$ & $\begin{array}{l}1.68 \\
1.27 \\
1.13 \\
1.36\end{array}$ & $\begin{array}{l}0.237 \\
0.058 \\
0.085 \\
0.086\end{array}$ \\
\hline $\begin{array}{l}\text { Ceftazidime } \\
\qquad \text { Mean }\end{array}$ & $\begin{array}{l}11.417 \\
22.283 \\
33.425\end{array}$ & $\begin{array}{l}11.17 \pm 0.17 \\
21.67 \pm 0.32 \\
32.83 \pm 0.21\end{array}$ & $\begin{array}{l}1.52 \\
1.48 \\
0.64 \\
1.21\end{array}$ & $\begin{array}{l}0.076 \\
0.143 \\
0.094 \\
0.104\end{array}$ \\
\hline
\end{tabular}

* Mean \pm standard deviation for five determinations

The performance of the methods was assessed by calculation of the $\mathrm{t}-$ and $\mathrm{F}$ values compared with the official method (12) and for The results showed that the calculated $\mathrm{t}$ - and F- values did not exceed the theoretical values (95\% confidence limits for five degree of freedom), Table 4 from which we can conclude that the proposed methods do not differ significantly from official method (12).

\section{Conclusion:}

The data given above reveal that the proposed methods are simple, accurate and sensitive with good precision and accuracy. With these methods, one can do the analysis with speed at law cost without losing accuracy. The proposed methods can be used as alternative methods to reported ones for the routine determination of cefotaxime sodium, cefuroxime sodium and ceftazidime pentahydrate in the pure form and in pharmaceutical vials. 


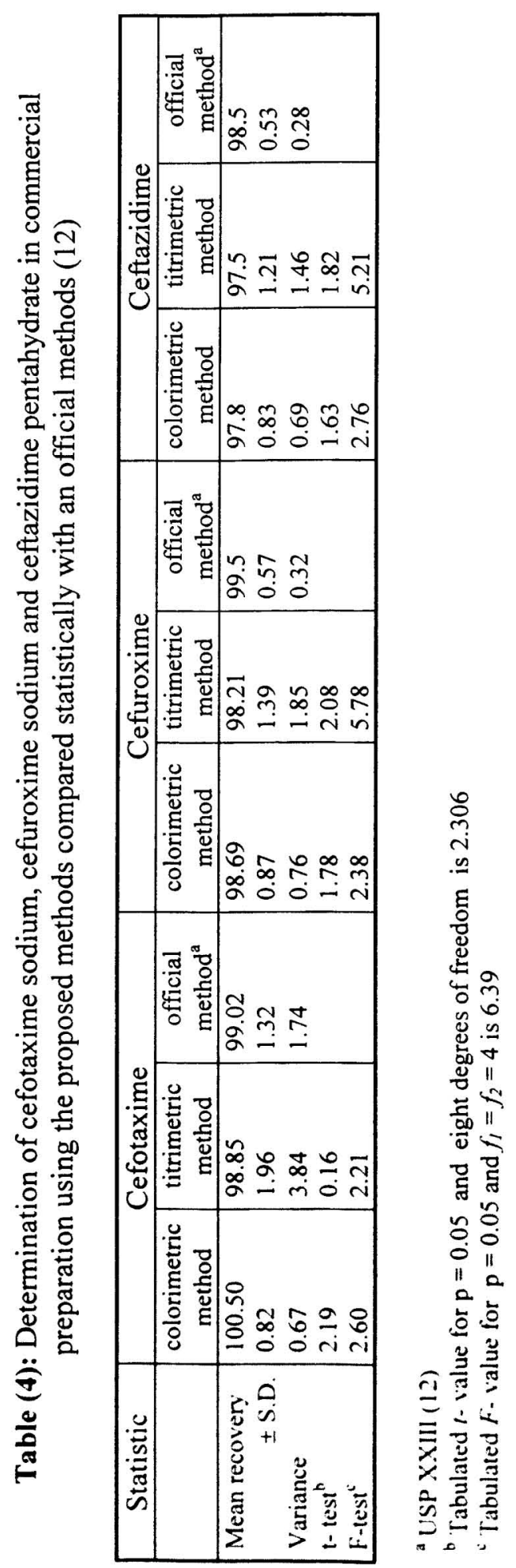




\section{REFERENCES}

1.Ayad M.M., Shalaby A.A., Abdellatef H.E. and EL-said H.M. (1999) J. Pharm. Biomed. Anal, 20, 557-564

2.Ayad M.M., Shalaby A.A., Abdellatef H.E. and EL-said H.M.(1999) J. Pharm. Biomed. Anal, 18, 975-983

3.Agbab D., Eric S., Karljikovic R., Vladimirov S., Zivanov S. and Stakic D. (1997) Spectrosc. Lett, 30, 309-319

4.AL-warthan A.A., Metwally F.H. and Al-Tamimi S.A. (1993) Anal. Lett, 26, 2619-2635

5.Galal S.M. (1991) Acta. Pharm. Jugosl, 41, 25-31

6.Campanero M.A., Zamarreno A.M., Simon M., Dios M.C. and Azanra J.R. (1997) Chromatographia, 46, 374-380

7.Rosseel M.T., Peleman R., Van-Hoorebeke H. and Pauwels R.A., J. Chromatogar (1997) 689, 438-441

8.Fabre H. and Castaneda-Penvalvo G.(1995) J. Liq. Chromatogr, 18, 3877-3887

9.Murllo J.A., Lemus J.M. and Garcia L.F.(1994) J. Pharm. Biomed. Anal, 12, 875-881

10.Ferreira V.S., Zanoni M.V.B., Furlan M. and Fogg A.G. (1997) Anal. Chim. Acta, 351, 105-114

11.Ferreira V.S., Zanoni M.V.B and Fogg A.G. (1997) Microchemical Journal, 57, 115-122

12.United States Pharmacopoeia XXIII, NF, US Pharmacopoeial Convention, Rockville, MD, 1995, p. 299, 315, 1540.

13.Van-Hoof F. and Heyndrickx A. (1974) Anal. Chem., 46, 268-288

14.Askal H.F., Abd-EL-Maged O.H. and Khashaba P.Y. (1995) Egypt. J. Anal. Chem, 4, 89-103

15. Casalini C., Cesrano G. and M ascellani G. (1977) Anal. Chem., $49,1002-1004$ 